\title{
Comprehensive clinical and genetic work-up of patients carrying single mtDNA deletions is warranted
}

\author{
Josef Finsterer \\ Klinik Landstrasse, Messerli Institute, Vienna, Austria \\ Correspondence to: Josef Finsterer, MD, PhD. Postfach 20, 1180 Vienna, Austria. Email: fifigs1@yahoo.de. \\ Response to: Liu R, Mo GL, Song YZ. Identification of a novel large deletion of the mitochondrial DNA in an infant with Pearson syndrome: a case \\ report. Transl Pediatr 2021;10:204-8.
}

Submitted Mar 01, 2021. Accepted for publication May 21, 2021.

doi: $10.21037 /$ tp-21-79

View this article at: https://dx.doi.org/10.21037/tp-21-79

With interest we read the article by Liu et al. about a 13 months old male with Pearson syndrome due to a novel, single mtDNA deletion of 4734 bp spanning from nucleotide 11220 to nucleotide 15953 (1). In addition to anemia, this novel mtDNA deletion manifested phenotypically with hepatopathy resulting in hepatomegaly, transient neutropenia, and lactic acidosis (1). It was concluded that the findings broaden the variant spectrum of single mtDNA deletions and stress the importance of considering a mitochondrial disorder (MID) in patients with anemia, liver dysfunction, and lactic acidosis and of choosing relevant genetic tools to unravel the genetic background of a MID (1). We have the following comments and concerns.

The main shortcoming of the study is that the heteroplasmy rate of the mtDNA deletion was not provided. Given the fact the patient developed normally with physical, cognitive, social, and language milestones typical for age after requiring transfusions for anemia and that nine mtDNA located genes (MTND4, MTTH, MTTS2, MTTL2, MTND5, MTND6, MTTE, MTCYB, MTTT) were deleted, it is quite likely that the heteroplasmy rate of the deleted mtDNA was low. Assuming that the heteroplasmy rate was high, a much more severe phenotype than the one of the index patient could be expected.

A second shortcoming is that no biochemical investigations of the respiratory chain were carried out. Given the fact that the phenotype was mild it can be assumed that respiratory chain functions were not or only mildly impaired. Since three genes encoding for subunits of complex-I were deleted at least a complex-I defect on biochemical investigations can be expected. However, deletion of various genes encoding tRNAs suggests that the activity of more than a single respiratory chain complex may be reduced.

A further shortcoming is that no muscle biopsy had been carried out. Given the fact that there was lactic acidosis, it is quite likely that the skeletal muscle was mildly or subclinically affected as well. Muscle is the main source of elevated serum lactate in MIDs.

Another shortcoming of the study is that the index patient was not prospectively investigated for involvement of organs other than the liver or the bone marrow. Since most patients with Pearson syndrome manifest not only with affection of the bone marrow or pancreas but with a multisystem syndrome $(2,3)$ or may develop KearnsSayre syndrome (KSS) (4) with progression of the disease, it is crucial that at least organs frequently affected in KSS, such as the brain, eyes, ears, endocrine organs, heart, kidneys, muscle and peripheral nerves are systematically investigated for mild or subclinical multiorgan involvement. Early recognition of multisystem involvement is crucial for initiating early symptomatic treatment and thus improving quality of life and outcome of an individual patient.

Missing is the urinary organic acid profile of the index patient. Though the urinary organic acid profile of patients with Pearson syndrome is frequently normal (5), there are some patients in whom lactate, 3-hydroxy-butyrate, 3-hydroxy-iso-butyrate, fumarate, pyruvate, 2-hydroxybutyrate, 2-ethyl-3-hydroxy-propionate, or 3-methylglutaconate are elevated (5).

The discrepancy between a "liver normal in size" as 
mentioned in the case description and "hepatomegaly" as mentioned at the beginning of the discussion should be clarified.

Overall, the interesting case report has a number of limitations which should be met before drawing conclusions. Particularly, we should be informed about heteroplasmy rates in affected and non-affected tissues, about results of biochemical investigations of affected tissues, about the muscle biopsy findings, about subclinical multiorgan involvement, and about the urinary organic acid profile. To increase the knowledge about rare disorders, such as Pearson syndrome, it is crucial to accumulate as much information from single patents as possible.

\section{Acknowledgments}

Funding: None.

\section{Footnote}

Provenance and Peer Review: This article was a standard submission to the journal. The article did not undergo external peer review.

Conflicts of Interest: The author has completed the ICMJE uniform disclosure form (available at https://dx.doi. org/10.21037/tp-21-79). The author has no conflicts of interest to declare.

Ethical Statement: The author is accountable for all aspects of the work in ensuring that questions related to the accuracy or integrity of any part of the work are

Cite this article as: Finsterer J. Comprehensive clinical and genetic work-up of patients carrying single mtDNA deletions is warranted. Transl Pediatr 2021;10(6):1755-1756. doi: 10.21037/ tp-21-79 appropriately investigated and resolved.

Open Access Statement: This is an Open Access article distributed in accordance with the Creative Commons Attribution-NonCommercial-NoDerivs 4.0 International License (CC BY-NC-ND 4.0), which permits the noncommercial replication and distribution of the article with the strict proviso that no changes or edits are made and the original work is properly cited (including links to both the formal publication through the relevant DOI and the license). See: https://creativecommons.org/licenses/by-nc-nd/4.0/.

\section{References}

1. Liu R, Mo GL, Song YZ. Identification of a novel large deletion of the mitochondrial DNA in an infant with Pearson syndrome: a case report. Transl Pediatr 2021;10:204-8.

2. Wild KT, Goldstein AC, Muraresku C, et al. Broadening the phenotypic spectrum of Pearson syndrome: Five new cases and a review of the literature. Am J Med Genet A 2020;182:365-73.

3. Broomfield A, Sweeney MG, Woodward CE, et al. Paediatric single mitochondrial DNA deletion disorders: an overlapping spectrum of disease. J Inherit Metab Dis 2015;38:445-57.

4. Lee HF, Lee HJ, Chi CS, et al. The neurological evolution of Pearson syndrome: case report and literature review. Eur J Paediatr Neurol 2007;11:208-14.

5. Semeraro M, Boenzi S, Carrozzo R, et al. The urinary organic acids profile in single large-scale mitochondrial DNA deletion disorders. Clin Chim Acta 2018;481:156-60. 